\title{
Article \\ Analyzing the Main Determinants for Being an Immigrant in Cuenca (Ecuador) Based on a Fuzzy Clustering Approach
}

\author{
Juan Carlos Martin ${ }^{1, *(D)}$, Natalia Soledad Bustamante-Sánchez ${ }^{2}$ and Alessandro Indelicato ${ }^{1}$ (D) \\ 1 Institute of Tourism and Sustainable Economic Development, University of Las Palmas de Gran Canaria, \\ 35017 Las Palmas de Gran Canaria, Spain; alessandro.indelicato101@alu.ulpgc.es \\ 2 Departamento de Ciencias Empresariales, Universidad Técnica Particular de Loja, Loja 110107, Ecuador; \\ nsbustamante@utpl.edu.ec \\ * Correspondence: jcarlos.martin@ulpgc.es
}

Citation: Martin, J.C.; BustamanteSánchez, N.S.; Indelicato, A.

Analyzing the Main Determinants for Being an Immigrant in Cuenca (Ecuador) Based on a Fuzzy Clustering Approach. Axioms 2022 11, 74. https://doi.org/10.3390/ axioms11020074

Academic Editor: Amit K. Shukla

Received: 29 December 2021

Accepted: 11 February 2022

Published: 14 February 2022

Publisher's Note: MDPI stays neutral with regard to jurisdictional claims in published maps and institutional affiliations.

Copyright: (c) 2022 by the authors. Licensee MDPI, Basel, Switzerland. This article is an open access article distributed under the terms and conditions of the Creative Commons Attribution (CC BY) license (https:// creativecommons.org/licenses/by/ $4.0 /)$.
Abstract: The study aims to analyze the determinants for being an immigrant in Cuenca (Ecuador). Our analysis is based on the answers given to a scale formed by 30 items included in a questionnaire administered to a representative sample of 369 immigrants. A fuzzy hybrid multi-criteria decisionmaking method, TOPSIS (Technique for Order Preference by Similarity to an Ideal Solution), is used to analyze whether immigrants are more or less exigent regarding the items included in the scale to reside in Cuenca. Then, a fuzzy clustering method is applied to analyze the differences observed in the main determinants observed over a number of traits according to their similarities to three obtained profiles: (1) extreme exigent immigrants; (2) extreme unneedful immigrants; and (3) intermediate exigent immigrants. Results show that items such as access to internet and benefits for retirees were highly valued by some immigrants. In addition, the authors found that information channels, reasons for immigrating, house location, main transport mode, income and main income source are the main determinants that differentiate whether the immigrants in Cuenca (Ecuador) are more or less demanding with respect to the exigency scale developed in the study. The main contributions to the body of knowledge, the policy implications and lines for future research are finally discussed.

Keywords: immigrants; fuzzy logic; triangular fuzzy numbers; TOPSIS; fuzzy-hybrid cluster

\section{Introduction}

The negative representations that immigrants have especially in Europe [1] are the result of the labels created by a polarization process that has distorted attitude formation over immigrants and refugees. The labels have important implications regarding the legitimacy of a newcomer's desire to settle in a country. Some of the negative attitudes towards immigrants are rooted in the perceived economic and cultural cost of having this group settling in Europe [2]. This negative perception of economic costs is particularly linked to developed welfare systems that provide houses, clothes, education and health care to immigrants. For this reason, a number of recent studies have found that attitudes towards immigrants in Western European countries are becoming more negative than in the past $[1,3-7]$.

The situation in the European countries contrasts highly with other less developed or developing countries, such as Ecuador, which are implementing programs that favor the entrance of immigrants, especially those who want to be retired in the country [8]. This wellknown phenomenon is also studied as second-home tourism or retirement migration [9]. There are a number of reasons that can influence the migrants in deciding whether to settle in another country; these depend on different traits, such as income, cultural background and lifestyle [10,11]. Martín and Bustamante-Sánchez [8] categorized the main reasons to be retired immigrants as: (1) improving the quality of life; (2) retiring and living in 
countries that they knew on their vacation; (3) looking for a lower cost of life and warmer climates; (4) moving out to escape from their home countries or to be away from relatives; (5) knowing different people, cultures and places; (6) relaxing in quieter cities and towns where they can live away from noise and globalization; and (7) adjusting the preferences according to the place attachment.

It is out of the scope of the current introduction to review the main theories that have been developed to explain the many controversies that exist in migrant studies. Interested readers are referred to [12], in which the authors discussed, in Chapter 2, the appreciation of who the immigrants are. Immigrant groups differed greatly by race, ethnic, age, income or religion. All these characteristics might put immigrants at risks of being seen as permanent and disadvantaged minorities separated from the majority. The authors compare the immigrants' integration to the US from Canada or the UK with the situation experienced by those who come from Latin America. Apart from integration, other topics of interests are related to national identity, political economy, distinctions between settler societies with a long immigration tradition vs. new immigrant societies and competing theories that explain the main reasons to emigrate to other countries.

As seen, the literature is abundant in the analysis of the attitudes towards immigrants from the perspective of the residents [1,7]. Nevertheless, the number of migrant studies analyzing the phenomenon from the perspective of immigrants is still scarce. It would be interesting to analyze why immigrants migrate to other countries. What are the main pull factors that a particular city needs to have or develop in order to attract the settlement of newcomers? In addition, the analysis of immigrants is equally uneven in favor of immigrants coming to the rich countries of the world for improving their well-being, but much less is known about the immigration processes from high-income countries to low-income countries. In this case, the well-being gain can be sustained by the existing tradeoff between the initial willingness to accept less quality in public services, such as the health system, libraries, and public administration, in exchange for the possibility of enjoying a better climate, nicer houses and relatively higher income than in their countries of origin. For example, Hayes [13] analyzed the notions of 'active' and 'successful' aging by exploring the narratives of aging for a group of retired immigrants from Canada and the US in Cuenca, Ecuador.

The present study attempts to correct, in part, the commented scarcity presenting empirical evidence of the most important determinants that Cuenca (Ecuador) has to be considered the place of settlement for a group of immigrants. The current study is based on a quantitative method grounded in fuzzy logic theory, a multi-criteria decisionmaking model and a fuzzy clustering method with the aim to provide interesting insights on: (1) obtaining the degree of exigency of immigrants (DEI) according the calculus of a synthetic index based on 30 items; (2) analyzing the level of exigency in every item with the help of the ideal solutions in order to determine if some items present more or less variability; (3) analyzing DEIs and sensitivity of results using some traits; (4) segmenting the immigrants without assuming that each immigrant belongs to only one segment; and (5) analyzing whether there are differences on the segments obtained according to some socioeconomic traits. Thus, the current study provides an empirical contribution to a body of knowledge that has been scarcely explored; the interest is justified because migration mainly from high-income countries to low-income countries is changing in less developed countries, such as Ecuador, and there is a need to understand the main pull factors that affect immigrants' decisions.

\section{Materials and Methods}

\subsection{Questionnaire and Data}

Unfortunately, we could not find any DEI scale that was previously developed by other researchers, so we decided to develop an instrument that contained the preferences of the immigrants related to what items are important or not when they decide to emigrate to a different country. At the end, the instrument consists of 30 items rated on a 5-point semantic 
response scale as follows: (1) not important at all; (2) slightly important; (3) somewhat important; (4) important; and (5) very important. The total scale score can be calculated as the sum of all individual item scores and can range from 30 to 150 . Higher scores indicate higher levels of degree of exigency related to the preferences of immigrants.

The development of the scale was obtained by identifying the diverse factors that were mentioned by other scholars in the analysis of the main determinants that lead individual to emigrate. There exists an ample consensus in the existing literature about the main causes for both flows immigrants and refugees [14]. Thus, the list of thirty items correspond to the categories of factors that include economic variables, globalization, political variables, social variables, cultural variables and access variables [15-30]. Other items were obtained from the items included in the studies of secondary houses as these are also related to the objective of the study [31-35].

A focus group with administrative officials of the city of Cuenca, as well as with a group of professors at the Universities of Loja and Cuenca in Ecuador and the University of Las Palmas de Gran Canaria in Spain was finally consulted in order to obtain the final list of the relevant items. Table 1 shows the final list of the 30 items included in the questionnaire to measure DEI.

Table 1. Items included in the degree of exigency of immigrants who live in Cuenca, Ecuador.

\begin{tabular}{|c|c|}
\hline Item & Description \\
\hline 1 & Climate \\
\hline 2 & Cost of Living \\
\hline 3 & Safety \\
\hline 4 & Language \\
\hline 5 & Local Culture \\
\hline 6 & General Image and Landscape \\
\hline 7 & Social Atmosphere ${ }^{1}$ \\
\hline 8 & Local Gastronomy \\
\hline 9 & Tourist Attractions \\
\hline 10 & Leisure and Entertainment \\
\hline 11 & Ease of integration \\
\hline 12 & Lifestyle \\
\hline 13 & Banks. Monetary Exchange \\
\hline 14 & Shops; Commercial Activity \\
\hline 15 & Accessibility of Roads \\
\hline 16 & Means of Transport \\
\hline 17 & Variety of Types of Houses \\
\hline 18 & House Rental Costs \\
\hline 19 & Quality of Water \\
\hline 20 & Quality of Air \\
\hline 21 & Quality of Grounds and Cleanliness \\
\hline 22 & General Vegetation/Green Space \\
\hline 23 & Medical Assistance \\
\hline 24 & Quality of Urban Services \\
\hline 25 & Access to Internet \\
\hline 26 & Tourist Services \\
\hline 27 & Education \\
\hline 28 & Programs for Foreigners \\
\hline 29 & Benefits for Retirees \\
\hline 30 & Sport facilities \\
\hline
\end{tabular}

${ }^{1}$ Social Atmosphere is related to social capital.

The questionnaire was divided into three different sections: (1) the first part included sociodemographic and economic information, such as nationality, gender, age, marital status, income and visa; (2) the second part included 26 items that measure the degree of importance given by respondents to buy a house in the city of Cuenca; and (3) the last part contained the items that measure DEI (Table 1). 
The questionnaire was administered in Cuenca during the months of January and February in the year 2018. The socioeconomic characteristics of the immigrants are relevant in the study in order to analyze the extent $D E I$ could be determined by income, age, visa permit or occupation. The sample size was determined by considering the data of the last census conducted by the National Institute of Census and Statistics, and knowing that the population of immigrants was approximately 9000 in the municipality, by applying the formula of finite population with a confidence level of 95 percent and an error margin of 5.0 percent, a representative sample of 369 immigrants who answered the questionnaires was obtained. To our surprise, we did not find any particular resistance of immigrants to participate in the survey, as we expected that some illegal immigrants could be more reluctant to be part of the survey process. In fact, it was well known that of the total 9000 immigrants, only 2422 were legal immigrants. The administration of the questionnaire was carried out face-to-face with the help of well-trained students, taking about 13 min to complete. A number of hot spots (19) were selected in the city to administer the questionnaires; these places were frequently used by the immigrants for entertainment, or for having coffee or a drink.

Table 2 shows the sociodemographic profile of the total sample of immigrants who responded to the questionnaire. Analyzing the most important categories for the sample of immigrants of some variables, namely nationality, gender, age, marital status and whether the immigrant was retired or not, it can be seen that: (1) nationalities of the US, Colombia, Canada, Argentina and Peru were those most represented; (2) there were slightly more males than females; (3) those between 25 and 34 years old, and between 35 and 44 years old were the two age groups more represented; (4) single and married were the most popular marital status; and (5) immigrants who were not retired were more abundant than retired immigrants, with a proportion of 4:1.

Table 2. Immigrants' Sociodemographic profiles.

\begin{tabular}{|c|c|c|c|}
\hline Variable & Categories & $\mathbf{N}$ & Perc. \\
\hline \multirow{16}{*}{ Nationality * } & United States & 76 & 20.60 \\
\hline & Colombia & 38 & 10.30 \\
\hline & Other South American countries & 32 & 8.67 \\
\hline & Canada & 30 & 8.13 \\
\hline & Argentina & 28 & 7.59 \\
\hline & Other nationality & 25 & 6.78 \\
\hline & Peru & 22 & 5.96 \\
\hline & France & 21 & 5.69 \\
\hline & Venezuela & 19 & 5.15 \\
\hline & Other European countries & 16 & 4.34 \\
\hline & Netherlands & 15 & 4.07 \\
\hline & Germany & 13 & 3.52 \\
\hline & Cuba & 10 & 2.71 \\
\hline & Italy & 9 & 2.44 \\
\hline & Mexico & 8 & 2.17 \\
\hline & Iberian countries & 7 & 1.90 \\
\hline \multirow{2}{*}{ Gender } & Male & 206 & 55.83 \\
\hline & Female & 163 & 44.17 \\
\hline \multirow{6}{*}{ Age } & $\leq 24$ years old & 45 & 12.20 \\
\hline & $2 \overline{5}-34$ years old & 116 & 31.44 \\
\hline & 35-44 years old & 83 & 22.49 \\
\hline & $45-54$ years old & 37 & 10.03 \\
\hline & 55-64 years old & 47 & 12.74 \\
\hline & $\geq 65$ years old & 41 & 11.11 \\
\hline
\end{tabular}


Table 2. Cont.

\begin{tabular}{cccc}
\hline Variable & Categories & N & Perc. \\
\hline \multirow{3}{*}{ Marital status } & Single & 164 & 44.44 \\
& Married & 125 & 33.88 \\
& Widowed & 16 & 4.34 \\
& Divorced & 40 & 10.84 \\
Retired & Unmarried couple & 24 & 6.50 \\
\hline \multirow{2}{*}{ Y } & N & 66 & 17.89 \\
& 303 & 82.11 \\
\hline
\end{tabular}

* There were 41 different nationalities, so for those with less than 10 respondents, it was decided to group them in territorial categories for ease of exposition.

\subsection{Methods}

\subsubsection{Fuzzy Set Theory Preliminaries}

The information provided by the instrument to measure $D E I$ is of a subjective and inaccurate nature because, as in many real world applications, preference knowledge is fuzzy rather than precise. Various methods have been developed by researchers to analyze this type of information. In this study, a fuzzy hybrid multi-criteria decision-making approach that integrates fuzzy logic and the technique of similarity to ideal solutions, TOPSIS (Technique for order preference by similarity to an ideal solution), was employed. This method has been successfully used in different fields [36-39].

The vagueness associated to the subjective evaluation is a sort of problem when researchers are finding a way to synthesize the information to apply econometric or mathematical models. Nevertheless, fuzzy logic models are adequate tools to deal in part with the vagueness associated with linguistic terms [40-42]. These models deal with the vague information deconstructing the idea of objective information in a sort of a measurement that that has different degrees of intensity. The degree of intensity is conceptualized by a probability (membership) function breaking into different pieces the objective "crisp information" that is conceptualized, following the fuzzy logic, as the zero-one membership function. This membership function is also known as the characteristic function, discrimination function or indicator function [43] (p.25).

We now introduce the basic terminology of fuzzy set theory as well as some of the algebraic operations based on [44-46]. A fuzzy set $\mathrm{A}$ in $\mathrm{X}$ is a function $\mathrm{A}: \mathrm{X} \rightarrow[0,1]$ denoted by $\mu_{A}$, and $\mathrm{X}$ is known as the universe or discourse. The value $\mu_{A}(x)$ at $x$ represents the membership function of $x$ in $\mathrm{A}$, and if the value is closer to one, then $x$ belongs to $\mathrm{A}$ with more intensity. The support of $A$ is denoted by $S(A)$ and can be found as all the elements $x$ in the discourse $\mathrm{X}$ for which $\mu_{A}(x)>0$. A is a normal fuzzy set in $\mathrm{X}$ if there exists an element $x$ for which $\mu_{A}(x)=1$. We finally introduce the $\alpha$-cut sets as they are important in the study of the fuzzy arithmetic. We define the $\alpha$-cut set $A_{\alpha}$ of the fuzzy set $\mathrm{A}$ as those elements $x$ in $\mathrm{X}$ for which $\mu_{A}(x) \geq \alpha$, where $\alpha \in(0,1]$.

Fuzzy numbers were first defined as "numbers that are close to a given real number" [46]. A fuzzy set $A$ in $\mathbb{R}$ is called a fuzzy number if it satisfies the following conditions: (1) A is a normal fuzzy set; (2) $A_{\alpha}$ is a closed interval for every $\alpha$ in $(0,1]$; and (3) the support of $\mathrm{A}$ is bounded.

The most common fuzzy numbers used by researchers are triangular fuzzy numbers (TFNs), defined by a triplet $\left(a_{1}, a_{2}, a_{3}\right)$ of real numbers for which the membership function is given in Equation (1).

$$
\mu_{A}(x)=\left\{\begin{array}{cc}
\frac{x-a_{1}}{a_{2}-a_{1}}, & a_{1} \leq x \leq a_{2} \\
\frac{x-a_{3}}{a_{2}-a_{3}}, & a_{2} \leq x \leq a_{3} \\
0, & \text { otherwise. }
\end{array}\right.
$$


The $\alpha$-cut set of the TFN $\left(a_{1}, a_{2}, a_{3}\right)$ is the closed interval $\left[a_{1}+\alpha\left(a_{2}-a_{1}\right), a_{3}-\alpha\left(a_{3}-a_{2}\right)\right]$. Now, let $A=\left(a_{1}, a_{2}, a_{3}\right)$ and $B=\left(b_{1}, b_{2}, b_{3}\right)$ be two TFNs, then with the help of the $\alpha$-cut sets, the following algebraic operations can be defined:

$$
\begin{gathered}
A(+) B=\left(a_{1}+b_{1}, a_{2}+b_{2}, a_{3}+b_{3}\right) \\
(-) A=\left(-a_{1},-a_{2},-a_{3}\right) \\
k A=\left(k a_{1}, k a_{2}, k a_{3}\right), k>0 \\
A(-) B=\left(a_{1}-b_{1}, a_{2}-b_{2}, a_{3}-b_{3}\right)
\end{gathered}
$$

In the study, each point of the semantic scale was assigned to a TFN [47,48]. Researchers have used different sets to represent the universe or discourse based on ranges $(0,1)$ or $(0,100)$ without loss of generality. The triplet for each point was selected according to previous experience or knowledge of researchers. Table 3 shows the TFNs used in the study. It is interesting to highlight that the central value of the semantic scale (somewhat important) presents the widest range (40 units) of all the TFNs used in the conversion. TFN membership function is characterized because the degree of the truth intensity is the highest in the intermediate point of the triplet used to represent it. Another interesting remark of the table is that the vagueness of the information is properly handled with fuzzy logic because all the consecutive TFNs overlap. A further discussion of the conversion can be consulted in [8].

Table 3. Five-point semantic scale conversion to TFNs.

\begin{tabular}{cc}
\hline Semantic Scale & TFN $^{\mathbf{1}}$ \\
\hline Not important at all & $(0,0,30)$ \\
Slightly important & $(20,30,40)$ \\
Somewhat important & $(30,50,70)$ \\
Important & $(60,70,80)$ \\
Very important & $(70,100,100)$ \\
\hline
\end{tabular}

${ }^{1}(0,1)$ interval for the universe is also common.

\subsubsection{A Hybrid Fuzzy TOPSIS Model}

The hybrid fuzzy TOPSIS model is an extension of the TOPSIS introduced by Hwang and Yoon [49]. This technique is based on the issue that the ideal solution should have the best level for all attributes considered in the analysis, whereas on the opposite, the negative ideal solution should be characterized by having all the worst attribute values. The hybrid fuzzy TOPSIS model is different from the original TOPSIS because the attribute values are represented by fuzzy numbers.

The fuzzy TOPSIS approach has been applied successfully in some previous studies in different fields, such as: (1) the hiring of a system analysis engineering by a software company [50]; (2) the selection of a location for a plant [51]; and (3) the selection of a location for a distribution center [52]. All the previous studies share in common the integration of various linguistic assessments in the form of fuzzy set numbers.

The respondents' information can be aggregated according to the objectives of the study by different population groups. This can be accomplished by calculating the average of the TFNs, and one of the good properties of the fuzzy hybrid model is that this operation is closed in the algebra of TFN [46]. Thus, the aggregated information of each group is also a TFN, and, for this reason, it can be inferred that it inherits the vagueness of the individual information [53]. Mathematically, the average TFN of a group of $n$ individuals is calculated as:

$$
\widetilde{A}=\left(a_{1}, a_{2}, a_{3}\right)=\left(\frac{1}{n}\right) \bullet\left(\widetilde{A}_{1} \oplus \widetilde{A}_{2} \oplus \cdots \widetilde{A}_{n}\right)=\left(\frac{\sum_{i=1}^{n} a_{1}^{(i)}, \sum_{i=1}^{n} a_{2}^{(i)}, \sum_{i=1}^{n} a_{3}^{(i)}}{n}\right)
$$


Once researchers have selected the number of groups they want to analyze, it is possible to calculate the fuzzy information matrix in which the rows are represented by each item included in the scale of the study and the columns are represented by the different groups under analysis. It is now where the hybrid nature of the method can be explained before applying the TOPSIS method to the TFN matrix. Two possible approaches can be utilized at this stage: TOPSIS can be applied to the TFN matrix that can be seen as a tensor matrix, or a defuzzification method can be applied to the TFN aggregated matrix before applying TOPSIS. In this sense, for example, Li [54] introduced a compromise ratio methodology for the fuzzy hybrid method when TOPSIS is directly applied to a fuzzy set of numbers to resolve a multi-attribute group decision-making problem.

The defuzzification method, also known as the clarification method, converts the fuzzy information matrix into a "crisp" information matrix. Thus, the crisp information value for the TFN needs to adequately synthesize the uncertainty associated to the TFN. There are many defuzzification methods that are based on different assumptions that can be made by the researchers, "mean of maximum", "center-of-area" and "alpha-cut" methods are among the most popular methods.

The defuzzification method used in the study is based on a "center of area" method and it is known as the best-non-fuzzy weighted average that can be calculated as $\left(\left(a_{1}+2 a_{2}+a_{3}\right) / 4\right)$. This method is very popular and has been proposed in many previous studies [8,55-57]. The method presents several advantages over other methods because it is simple and does not require any personal researcher value judgment. Thus, the TFN information matrix is converted to a conventional crisp information matrix.

TOPSIS is then applied to the information matrix method [49,58]. The ideal solutions are obtained according to items used to measure DEI and the groups used in the analysis. The items need to be separated according to whether higher or lower values mean more or less value for the synthetic indicator that is constructed. Mathematically, the positive and negative ideal solutions are, in our case, calculated as:

$$
\begin{aligned}
& A^{+}=\left\{\left(\max V_{i g} \mid i \in I\right),\left(\min V_{i g} \mid i \in I^{\prime}\right), g=1,2, \ldots, G \equiv \text { groups }\right\}, \\
& A^{-}=\left\{\left(\min V_{i g} \mid i \in I\right),\left(\max V_{i g} \mid i \in I^{\prime}\right), g=1,2, \ldots, G \equiv \text { groups }\right\},
\end{aligned}
$$

where $I$ and $I^{\prime}$ divide the different items included in the DEI scale according to benefit (higher values are good) or cost (higher values are bad) characteristics regarding the indicator under analysis. In the current study, the whole set of 30 items included in the $D E I$ scale can be considered as a benefit, and the number of groups $G$ depends on are the categories of 17 covariates, such as nationality, gender, age, marital status, occupation, years of residence, residence visa, pension visa, main information channels, reasons to come, house location, house tenancy, house type, main transport mode used, income, main income source and expenditure in the city. A total number of 84 groups were considered in the study.

Once the ideal solutions are calculated, the relative DEI index for each group can be calculated comparing the existing distance from each group to these ideal solutions calculated in Equation (6). Thus, the synthetic DEI indicator for the groups can be obtained as:

$$
\begin{gathered}
S_{g}^{+}=\operatorname{dist}\left(V_{g}, A^{+}\right)=\sqrt{\sum_{i=1}^{30}\left(V_{i g}-A_{i}^{+}\right)^{2}} g=1,2, \ldots, G \\
S_{g}^{-}=\operatorname{dist}\left(V_{g}, A^{-}\right)=\sqrt{\sum_{i=1}^{30}\left(V_{i g}-A_{i}^{-}\right)^{2}} g=1,2, \ldots, G, \\
D E I_{g}=\frac{S_{g}^{-}}{S_{g}^{+}+S_{g}^{-}} g=1,2, \ldots, G
\end{gathered}
$$

where $D E I$ is always in the range $(0,1)$. Thus, each of the groups included in the analysis can be ranked according to whether the group is more or less exigent according to the 
increasing order of the synthetic index. TOPSIS is based on the concept that the best alternatives should be more or less similar to the positive or negative ideal solutions.

The synthetic exigency DEI index depends on 30 different items and, sometimes, the knowledge of what items are more or less critical to different groups can be the object of interest for some stakeholders, such as policy makers in charge of the immigrant governance rules. Thus, the elasticity value measuring the sensitivity of $D E I$ with respect to each item will be obtained. Mathematically, the elasticity of the DEI for each group $s$ and each item $i$ can be calculated as:

$$
\eta_{i g}=\frac{\Delta \% D E I_{g}}{\Delta \% V_{i g}}=\frac{d D E I_{g}}{d V_{i g}} \frac{V_{i g}}{D E I_{g}},
$$

\subsubsection{Fuzzy Clustering Method}

D’Urso [59] discussed different fuzzy clustering models for fuzzy data according to: (1) the informational paradigms and their relationship with the fuzzy clustering methods; (2) fuzzy data features regarding the algebraic and geometric formalization, mathematical transformations and metrics; (3) conceptual aspects, such as elicitation and specification of the membership functions; (4) a systematic overview with a comparative assessment of different fuzzy clustering methods; and (5) an analysis of fuzzy clustering model extensions for complex fuzzy data structures, such as fuzzy data time arrays. The reference is a good starting point to find the main pioneering fuzzy clustering studies in which a great deal of attention was paid to the fuzzy clustering analysis for fuzzy data.

The rest of the section briefly describes the three fuzzy cluster solutions adopted in the study. On occasions, it is preferable to obtain a three-cluster solution rather than a solution with more than three clusters, even though a statistical indicator might suggest that it is more reasonable to obtain more than three clusters [60]. Thus, three representative immigrant profiles were obtained and named as: (1) extreme exigent immigrant; (2) extreme unneedful immigrant; and (3) intermediate exigent immigrant. The fuzzy clustering method provides the membership function assigned to each immigrant that determines the probability that each immigrant has to belong to each of the three clusters. The profiles of the representative immigrant for each of the clusters were based on the individual DEI indicator according to the maximum, minimum and median values. This assumption is very different from other proposed methods in which the prototypes are obtained directly within the method.

Cluster analysis summarizes multivariate data in order to find useful information that facilitates the decision making. Cluster analysis finds meaningful groups for which the similarities within the clusters and the dissimilarity between the groups are maximized [61] The fuzzy cluster algorithm is presented in Equation (8). The method is an extension of the bagged cluster algorithm introduced by Leisch [62]. The fuzzy $C$ means the algorithm for fuzzy data (FCM-FD) can be expressed as follows:

$$
\left\{\begin{array}{c}
\min : \sum_{i=1}^{n} \sum_{c=1}^{c} u_{i c}^{m} d_{F}^{2}\left(\widetilde{x}_{i}, \widetilde{p}_{c}\right)=\sum_{i=1}^{n} \sum_{c=1}^{c} u_{i c}^{m}\left[w_{2}^{2}\left\|a_{2}^{i}-p_{2}^{c}\right\|^{2}+\right. \\
\left.+w_{1}^{2}\left(\left\|a_{1}^{i}-p_{1}^{c}\right\|^{2}+\left\|a_{3}^{i}-p_{3}^{c}\right\|^{2}\right)\right] \\
\text { s.t. } \quad \begin{array}{c}
m>1, u_{i c} \geq 0, \sum_{c=1}^{c} u_{i c}=1, \\
w_{1} \geq w_{2} \geq 0, w_{1}+w_{2}=1
\end{array},
\end{array},\right.
$$

where, $d_{F}^{2}\left(\widetilde{x}_{i}, \widetilde{p}_{c}\right)$ represents the squared fuzzy distance between the $i$ th immigrant and the profile of the $c$ th cluster; the $\widetilde{x}_{i} \equiv\left\{\widetilde{x}_{i k}=\left(a_{1 i k}, a_{2 i k}, a_{3 i k}\right): k=1 \ldots K\right\}$ denotes the TFN triplet for the ith immigrant obtained from the observation of the 30 items; $\widetilde{p}_{c} \equiv\left\{\tilde{p}_{c k}=\left(p_{1 c k}, p_{2 c k}, p_{3 c k}\right): k=1 \ldots K\right\}$ represents the fuzzy profile of the $c$ th cluster; $\left\|a_{2}^{i}-p_{2}^{c}\right\|^{2}$ is the squared Euclidian distance between the centers of the TFN vectors of the $i$ th immigrant and the representative immigrant of the $c$ th cluster; $\left\|a_{1}^{i}-p_{1}^{c}\right\|^{2}$ and 
$\left\|a_{3}^{i}-p_{3}^{c}\right\|^{2}$ are the squared Euclidian distances between the left and right extreme components of the TFN vectors of the $i$ th immigrant and the representative immigrant of the $c$ th cluster, respectively; $w_{1} \geq w_{2} \geq 0$ are suitable weights for the center and extreme components for the fuzzy distances considered; $m>1$ is a weighted exponent that controls the fuzziness of the obtained partition; $u_{i c}$ gives the membership degree of the $i$ th immigrant in the $c$ th cluster.

There are a number of methodological issues associated with the fuzzy cluster analysis proposed in the study, such as the selection of the centroids or medoids, the distance measures, the selection of the parameters $m, w_{1}$ and $w_{2}$, and the optimal solutions of the method. The medoids strategy is preferred as the profiles of the representing cluster prototypes are real observations. As mentioned, our study is based on selecting three real observations for the prototypes of each cluster. Different distance measures can be adapted to the fuzzy environment, such as a sort of exponential-type distance measure, Hausdorff metrics or dissimilarity parametric approaches. The study uses a parametric dissimilarity approach composed of two distances, the center and spread distances, that are related to the values of the $w$ coefficients. The coefficient $m$ is known as the "fuzziness coefficient". The fuzziness directly increases with $m$, and when $m$ is closer to one, the fuzziness is lower. In this study, $m$ is equal to 1.5 as in [60]. The weights $w_{1}$ and $w_{2}$ measure the relative importance given to each of the components of the triplet that represent the respective TFN. In this study, as in other empirical applications, the neutral approach was selected and, accordingly, the weights are equal to $0.5[56,60]$.

We end this section with the optimal solutions provided by the Lagrangian multiplier method used to solve the constrained minimization problem. D'Urso and Giordani [63] discussed that the Lagrangian method does not guarantee that the global optimum is obtained, so in order to check the stability of the solution, they suggested to initialize the iterative algorithm by considering several different starting points. The authors used an iterative algorithm in which the weights are directly obtained within the model (internal weighting estimation). As stated, our study uses the neutral approach in which we have not tuned the influence of the two components of the TFNs in the clustering process, and the local optima problem might be less important than in the case in which the prototypes and the weights are determined in the own method. Interested readers in cluster validation and cluster profiles are referred to $[59,60,63-65]$.

\section{Results}

\subsection{Fuzzy Hybrid Model}

Table 4 shows the TFNs and the defuzzified (crisp) values that correspond to the total sample of immigrants. A simple analysis of the TFN triplets shows that the information has a clear meaning for fuzzy logic experts, but it is less evident for those who are not so familiar with this tool. It can be seen that the majority of the TFNs overlap. However, this is not the case for the most and least valued items which are quality of water and sport facilities, respectively. The overlapping finding is not a surprise as this is an essential characteristic of the fuzzy logic approach to deal with vague information. The defuzzification method provides the crisp column and facilitates the interpretation of the information. Thus, it can be inferred that the items for which the degree of exigency is higher than 75 are quality of urban services, programs for foreigners, house rental costs, climate, lifestyle, ease of integration, safety, cost of living, medical assistance and quality of water. Meanwhile, there are only two items, sport facilities and education, for which the crisp values are lower than 50 , so immigrants are clearly less exigent in these two items. 
Table 4. TFN and crisp values of the total sample of immigrants by item and ideal solutions ${ }^{1}$.

\begin{tabular}{lllll}
\hline Item & TFN & Crisp & $\mathbf{A}^{+}$ & $\mathbf{A}^{-}$ \\
\hline Climate & $(58.78,79.92,86.59)$ & 76.30 & 89.69 & 59.44 \\
Cost of Living & $(61.65,86.04,90.60)$ & 81.08 & 92.50 & 64.03 \\
Safety & $(61.76,83.55,88.27)$ & 79.28 & 92.50 & 53.91 \\
Language & $(44.42,61.11,74.23)$ & 60.22 & 70.00 & 51.41 \\
Local Culture & $(45.07,60.79,74.55)$ & 60.30 & 72.31 & 50.00 \\
General Image and Landscape & $(46.83,62.44,75.37)$ & 61.77 & 70.58 & 50.00 \\
Social Atmosphere & $(50.33,65.45,77.15)$ & 64.59 & 75.19 & 54.31 \\
Local Gastronomy & $(42.93,58.48,72.66)$ & 58.14 & 70.68 & 48.21 \\
Tourist Attractions & $(50.95,65.45,76.53)$ & 64.59 & 78.86 & 40.56 \\
Leisure and Entertainment & $(54.25,72.22,81.41)$ & 70.03 & 92.50 & 59.06 \\
Ease of integration & $(59.81,81.65,87.40)$ & 77.63 & 92.50 & 55.00 \\
Lifestyle & $(59.81,80.70,87.05)$ & 77.07 & 92.50 & 63.75 \\
Banks. Monetary Exchange & $(56.59,78.43,84.91)$ & 74.59 & 92.50 & 36.72 \\
Shops. Commercial Activity & $(44.77,61.65,74.63)$ & 60.68 & 78.64 & 38.33 \\
Accessibility of Roads & $(35.72,51.57,66.78)$ & 51.41 & 65.45 & 42.92 \\
Means of Transport & $(36.72,51.60,66.23)$ & 51.54 & 64.22 & 44.50 \\
Variety of Types of Houses & $(51.65,67.15,78.02)$ & 66.00 & 77.50 & 53.75 \\
House Rental Costs & $(59.05,79.30,86.12)$ & 75.94 & 92.50 & 62.63 \\
Quality of Water & $(66.29,92.41,94.88)$ & 86.50 & 92.50 & 73.28 \\
Quality of Air & $(60.46,76.67,84.42)$ & 74.55 & 81.25 & 59.86 \\
Quality of Grounds and Cleanliness & $(47.07,64.12,77.51)$ & 63.20 & 77.41 & 50.00 \\
General Vegetation/Green Space & $(49.59,66.26,78.21)$ & 65.08 & 74.13 & 50.00 \\
Medical Assistance & $(65.15,91.65,94.50)$ & 85.74 & 92.50 & 60.78 \\
Quality of Urban Services & $(58.92,78.10,85.34)$ & 75.12 & 92.50 & 57.97 \\
Access to Internet & $(54.80,71.25,80.70)$ & 69.50 & 92.50 & 48.00 \\
Tourist Services & $(48.75,63.33,76.12)$ & 62.89 & 73.13 & 49.58 \\
Education & $(34.85,49.89,64.93)$ & 49.89 & 87.68 & 37.17 \\
Programs for Foreigners & $(56.69,79.59,85.58)$ & 75.37 & 92.50 & 52.81 \\
Benefits for Retirees & $(44.23,61.54,73.50)$ & 60.20 & 92.50 & 37.68 \\
Sport facilities & $(34.85,49.30,64.07)$ & 49.38 & 81.56 & 33.28 \\
\hline A and A- are the & $(4.50)$ & & &
\end{tabular}

${ }^{1} \mathrm{~A}^{+}$and $\mathrm{A}^{-}$are the positive and negative ideal solutions respectively (Equations (4) and (5)).

The ideal solutions were calculated according to Equations (4) and (5). Through analysis of the ideal solutions (Table 4), it is a surprise that the positive ideal solutions are represented by the highest mark in some items as, for example, cost of living, safety, access to internet, programs for foreigners or benefits for retirees. These results are very different from those obtained in the negative ideal solution in which all the groups of immigrants do not value some item at its minimum value (not important at all). There are 11 items for which the figures are lower than 50 . The percentage variation between the values of the positive and negative ideal solutions can be used to conclude that four items are seen more homogeneously by the immigrants, namely quality of water and air, language and social atmosphere. The item which is seen as more heterogeneous is banks and monetary exchange.

Table 5 shows the DEI synthetic index obtained according to Equation (6) for the group of groups that were already commented on in Table 1 . The results show that by nationality the most exigent immigrants are from Peru, Mexico, Venezuela and Cuba. It is interesting to remark that all the countries are located in South America. Female immigrants are more exigent than male immigrants. The senior group ( $>=65$ years old) are the most exigent immigrants if the analysis is performed by age. The analysis by marital status shows that widowed and unmarried couple immigrants are the most exigent groups. And finally, retired immigrants are more exigent than non-retired immigrants. 
Table 5. DEI synthetic index.

\begin{tabular}{|c|c|c|}
\hline Variable & Categories & $D E I$ \\
\hline \multirow{16}{*}{ Nationality } & Germany & 0.523 \\
\hline & Argentina & 0.525 \\
\hline & Other nationality & 0.454 \\
\hline & Other European countries & 0.455 \\
\hline & Other South American countries & 0.510 \\
\hline & Canada & 0.484 \\
\hline & Colombia & 0.562 \\
\hline & Cuba & 0.600 \\
\hline & Iberian countries & 0.518 \\
\hline & United States & 0.427 \\
\hline & France & 0.491 \\
\hline & Netherlands & 0.526 \\
\hline & Italy & 0.347 \\
\hline & Mexico & 0.623 \\
\hline & Peru & 0.625 \\
\hline & Venezuela & 0.623 \\
\hline \multirow{2}{*}{ Gender } & Male & 0.474 \\
\hline & Female & 0.547 \\
\hline \multirow{6}{*}{ Age } & $\leq 24$ years old & 0.480 \\
\hline & $2 \overline{5}-34$ years old & 0.501 \\
\hline & $35-44$ years old & 0.514 \\
\hline & $45-54$ years old & 0.529 \\
\hline & 55-64 years old & 0.482 \\
\hline & $\geq 65$ years old & 0.542 \\
\hline \multirow{5}{*}{ Marital status } & Single & 0.490 \\
\hline & Married & 0.515 \\
\hline & Widowed & 0.583 \\
\hline & Divorced & 0.498 \\
\hline & Unmarried couple & 0.531 \\
\hline \multirow{2}{*}{ Retired } & Yes & 0.518 \\
\hline & No & 0.504 \\
\hline
\end{tabular}

Table 6 shows the elasticities of the total sample of immigrants and the marital status groups with respect to each of the items. The figures of the table can be used to conclude that $D E I$ is quite inelastic with respect to all the items and for the total sample of immigrants and for all of the marital status groups under analysis. The table can be analyzed bidimensionally by item and group. Focusing first in the whole sample, it can be concluded that the items for which the total sample is more elastic are: (1) banks and monetary exchange; (2) benefits for retirees; and (3) access to internet. On the other hand, DEI for the whole sample of immigrants is more inelastic with respect to these three items: (1) language; (2) accessibility of roads; and (3) means of transport.

Table 6. Elasticity values of the total sample and age groups.

\begin{tabular}{|c|c|c|c|c|c|c|}
\hline Item & Total & Single & Married & Widowed & Divorced & Unmarried Couple \\
\hline Climate & 0.1254 & 0.1284 & 0.1194 & 0.0793 & 0.1274 & 0.1100 \\
\hline Cost of Living & 0.1252 & 0.1329 & 0.1192 & 0.0896 & 0.1251 & 0.1067 \\
\hline Safety & 0.1654 & 0.1729 & 0.1615 & 0.1147 & 0.1592 & 0.1382 \\
\hline Language & 0.0611 & 0.0620 & 0.0602 & 0.0478 & 0.0600 & 0.0530 \\
\hline Local Culture & 0.0735 & 0.0749 & 0.0707 & 0.0555 & 0.0783 & 0.0637 \\
\hline General Image and Landscape & 0.0690 & 0.0712 & 0.0664 & 0.0443 & 0.0719 & 0.0584 \\
\hline Social Atmosphere & 0.0736 & 0.0766 & 0.0707 & 0.0556 & 0.0770 & 0.0626 \\
\hline Local Gastronomy & 0.0715 & 0.0727 & 0.0704 & 0.0562 & 0.0681 & 0.0623 \\
\hline Tourist Attractions & 0.1340 & 0.1437 & 0.1289 & 0.0985 & 0.1269 & 0.1144 \\
\hline
\end{tabular}


Table 6. Cont.

\begin{tabular}{|c|c|c|c|c|c|c|}
\hline Item & Total & Single & Married & Widowed & Divorced & Unmarried Couple \\
\hline Leisure and Entertainment & 0.1289 & 0.1357 & 0.1235 & 0.1122 & 0.1248 & 0.1121 \\
\hline Ease of integration & 0.1578 & 0.1723 & 0.1470 & 0.1181 & 0.1596 & 0.1342 \\
\hline Lifestyle & 0.1211 & 0.1232 & 0.1183 & 0.0922 & 0.1176 & 0.1062 \\
\hline Banks. Monetary Exchange & 0.2246 & 0.2263 & 0.2200 & 0.1588 & 0.2297 & 0.2036 \\
\hline Shops. Commercial Activity & 0.1330 & 0.1389 & 0.1297 & 0.1003 & 0.1201 & 0.1259 \\
\hline Accessibility of Roads & 0.0636 & 0.0668 & 0.0609 & 0.0494 & 0.0609 & 0.0541 \\
\hline Means of Transport & 0.0559 & 0.0562 & 0.0540 & 0.0370 & 0.0538 & 0.0500 \\
\hline Variety of Types of Houses & 0.0854 & 0.0877 & 0.0820 & 0.0560 & 0.0818 & 0.0753 \\
\hline House Rental Costs & 0.1241 & 0.1301 & 0.1194 & 0.1013 & 0.1150 & 0.1114 \\
\hline Quality of Water & 0.0897 & 0.0938 & 0.0861 & 0.0574 & 0.0897 & 0.0741 \\
\hline Quality of Air & 0.0860 & 0.0896 & 0.0832 & 0.0508 & 0.0858 & 0.0715 \\
\hline Quality of Grounds and Cleanliness & 0.0946 & 0.0967 & 0.0913 & 0.0674 & 0.0948 & 0.0818 \\
\hline General Vegetation/Green Space & 0.0850 & 0.0913 & 0.0798 & 0.0532 & 0.0871 & 0.0709 \\
\hline Medical Assistance & 0.1459 & 0.1548 & 0.1392 & 0.0881 & 0.1474 & 0.1204 \\
\hline Quality of Urban Services & 0.1415 & 0.1449 & 0.1397 & 0.1133 & 0.1388 & 0.1216 \\
\hline Access to Internet & 0.1688 & 0.1762 & 0.1626 & 0.1349 & 0.1712 & 0.1419 \\
\hline Tourist Services & 0.0804 & 0.0858 & 0.0768 & 0.0579 & 0.0757 & 0.0694 \\
\hline Education & 0.1393 & 0.1484 & 0.1326 & 0.1214 & 0.1216 & 0.1312 \\
\hline Programs for Foreigners & 0.1625 & 0.1681 & 0.1585 & 0.1236 & 0.1623 & 0.1397 \\
\hline Benefits for Retirees & 0.1809 & 0.1645 & 0.1885 & 0.1561 & 0.2001 & 0.1453 \\
\hline Sport facilities & 0.1312 & 0.1399 & 0.1239 & 0.1062 & 0.1334 & 0.1118 \\
\hline
\end{tabular}

A similar analysis can be carried out now for each of the marital status groups included in the table, but for ease of exposition and in order to synthesize and be concise, the analysis will be based on the overall results for the five groups, namely single, married, widowed, divorced and unmarried couple. Thus, the analysis will be based on the 10 highest figures (more elastic pair group item) and the 10 lowest figures (more inelastic pair group item). Thus, we conclude that regarding the items, ease of integration is added to the list of the elastic items obtained for the whole sample, and that the more elastic groups are those whose marital status is single or divorced.

Analyzing the 10 more inelastic pair group items in the table, it can be seen that quality of air and green space are the two items that are now included in the list of the items for the whole sample mentioned above. The analysis by group concludes that widowed immigrants now have six of the most inelastic pairs, so it seems that this group is more inelastic than the rest of marital status groups.

\subsection{The Fuzzy Clusters}

Table 7 shows the three representative profiles of each cluster, and for clarity, it was decided to present the semantic scale answers instead of the respective converted TFN. For this reason, the table shows a vector of 30 values in the range 1 to 5 for each of the representative immigrants selected for each of the clusters, namely extreme exigent immigrant, extreme unneedful immigrant and intermediate exigent immigrant. The first cluster is characterized by those immigrants for which DEI synthetic indicator is closer to 1 . The second cluster, on the other hand, is characterized by those immigrants who are the least exigent. And finally, the third cluster is an intermediate cluster that represents quite well the greyness area between the other two extreme clusters. 
Table 7. Representatives for the clusters.

\begin{tabular}{|c|c|c|c|}
\hline Item & $\begin{array}{l}\text { Extreme } \\
\text { Exigent }\end{array}$ & $\begin{array}{c}\text { Extreme } \\
\text { Unneedful }\end{array}$ & Intermediate \\
\hline Climate & 5 & 3 & 4 \\
\hline Cost of Living & 5 & 1 & 5 \\
\hline Safety & 5 & 1 & 5 \\
\hline Language & 5 & 1 & 4 \\
\hline Local Culture & 5 & 1 & 4 \\
\hline General Image and Landscape & 5 & 1 & 4 \\
\hline Social Atmosphere & 5 & 1 & 4 \\
\hline Local Gastronomy & 5 & 1 & 4 \\
\hline Tourist Attractions & 5 & 1 & 5 \\
\hline Leisure and Entertainment & 5 & 1 & 3 \\
\hline Ease of integration & 5 & 1 & 4 \\
\hline Lifestyle & 5 & 1 & 5 \\
\hline Banks. Monetary Exchange & 5 & 1 & 5 \\
\hline Shops. Commercial Activity & 5 & 1 & 4 \\
\hline Accessibility of Roads & 5 & 1 & 2 \\
\hline Means of Transport & 5 & 1 & 2 \\
\hline Variety of Types of Houses & 5 & 1 & 4 \\
\hline House Rental Costs & 5 & 1 & 4 \\
\hline Quality of Water & 5 & 1 & 5 \\
\hline Quality of Air & 5 & 1 & 4 \\
\hline Quality of Grounds and Cleanliness & 5 & 1 & 3 \\
\hline General Vegetation/Green Space & 5 & 1 & 4 \\
\hline Medical Assistance & 5 & 1 & 5 \\
\hline Quality of Urban Services & 5 & 1 & 5 \\
\hline Access to Internet & 5 & 1 & 5 \\
\hline Tourist Services & 5 & 1 & 4 \\
\hline Education & 5 & 1 & 1 \\
\hline Programs for Foreigners & 5 & 1 & 5 \\
\hline Benefits for Retirees & 5 & 1 & 4 \\
\hline Sport facilities & 5 & 1 & 3 \\
\hline
\end{tabular}

By analysis of Table 7, it can be seen that the representative for the extreme exigent immigrant is characterized by an immigrant who perceives all the items of the scale at the maximum value. The profile of the immigrant was an American retired and widowed woman in the senior age group scale who obtained the visa by investments and lived in a rented house. It is interesting to remark that the score of the scale for the immigrant is the maximum of 150. In empirical applications, when the scale has a relatively large number of items, this result is not common $[38,65]$. On the contrary, analysis of the extreme unneedful immigrant is very different as it can be seen that the representative is an immigrant who answered all the items with the minimum value with the exception of the climate that is valued as somewhat important. In this case, the score of the scale was 32 and not the minimum 30. The profile for this immigrant was a Bolivian woman of middle age between 35 and 44 years old who lived with an unmarried couple, worked and her house was borrowed. The representative immigrant for the intermediate cluster is characterized by: (1) three low valued items with a value of 1 (education) and a value of 2 (accessibility of roads and means of transport); (2) three intermediate valued items with a value of 3 (leisure and entertainment, quality of grounds and cleaning, and sport facilities); and (3) 24 high valued items with 14 and 10 items showing values of 4 and 5, respectively. Interestingly, it can be seen that the score of the scale for the intermediate exigent immigrant is 120, so the preferences are closer to the extreme exigent immigrant than to the extreme unneedful immigrant. The profile of the representative is characterized for being a married Dutch woman of middle age (35-44 years old) who worked and lived in a rented house.

Figure 1 shows the ternary plot of the whole sample of immigrants. The ternary plots represent graphically how the immigrants are distributed in the triangle according 
to the probability vector (weights) that characterizes the membership function that each immigrant has to belong to in each of the three clusters. The graph provides a very intuitive understanding about how the immigrants are distributed with respect to the resemblance of being more similar to extreme exigent, extreme unneedful or intermediate. At a simple glance, it seems that the majority of the immigrants are located near the base line that joins extreme exigent and intermediate immigrants. The immigrants near the upper vertex that characterizes the extreme unneedful immigrants are less in number. A summary of the graph can be obtained by the average probabilities for each of the clusters, which is as follows: (1) $26.4 \%$ for the extreme exigent cluster; (2) $4.1 \%$ for the extreme unneedful cluster; and (3) $69.4 \%$ for the intermediate cluster. The summary matches well with the distribution of the immigrants in the triangle. Thus, it can be concluded that the immigrants in Cuenca are a mixture of extreme or intermediate exigent people, and only a very small group of immigrants can be considered unneedful ones.

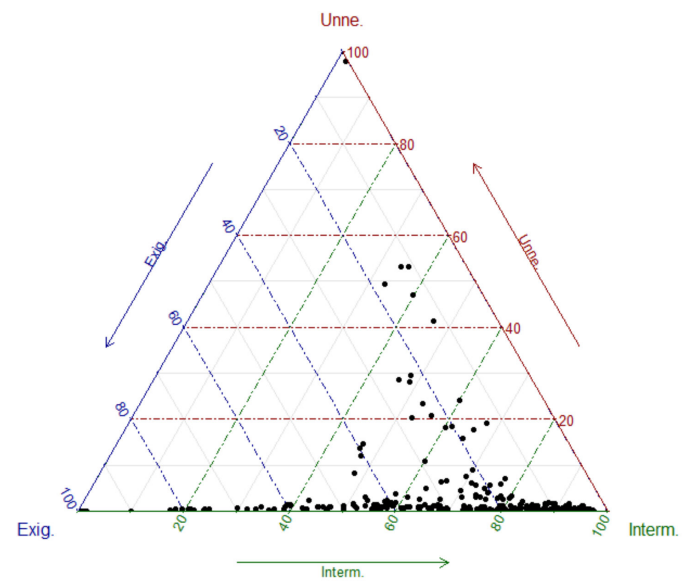

Figure 1. Immigrants' fuzzy clustering ternary graph.

This section ends with a final ANOVA analysis in which the socioeconomic variables that can affect the membership function of the fuzzy clustering method are studied. The analysis will be based on ANOVA and Tukey-Kramer coefficients, and 17 different socioeconomic and demographic variables have been used as factors to analyze differences in the distribution of immigrants according to the fuzzy clusters: (1) nationality; (2) gender; (3) age; (4) marital status; (5) occupation; (6) years of residence; (7) visa of residence; (8) visa by pension; (9) main information channels; (10) reason to come; (11) house location; (12) house tenancy; (13) house type; (14) main transport mode; (15) income; (16) main income source; and (17) expenditure in the city. Interestingly, the main sociodemographic variables, such as nationality, gender, age and marital status do not have any effect on the distribution of the fuzzy clusters. The variables that have a significant effect on the distribution are characterized by being from the economic sphere or inherent to immigrants lifestyle. Table 8 presents the ANOVA results and the discussion of the differences observed for the factors that have a significant effect, namely on information channels, reasons to come, house location, main transport mode, income and main income source. The expenditure in the city was also a significant factor but has been omitted because the discussion is similar to that of income. The factors that do not have a significant effect are omitted from the table. 
Table 8. ANOVA results.

\begin{tabular}{|c|c|c|c|c|c|c|c|}
\hline Variable & Categories & Exigent $^{1}$ & Unneeded $^{1}$ & Interm. $^{1}$ & E.p ${ }^{2}$ & U.p ${ }^{2}$ & I.p ${ }^{2}$ \\
\hline \multirow{5}{*}{$\begin{array}{l}\text { Information } \\
\text { channel }\end{array}$} & Internet & $26.4 \%$ & $3.2 \%$ & $70.4 \%$ & \multirow{5}{*}{0.0190} & \multirow{5}{*}{0.0000} & \multirow{5}{*}{0.0000} \\
\hline & Social Media & $24.0 \%$ & $2.4 \%$ & $73.6 \%$ & & & \\
\hline & Specialized Media & $23.6 \%$ & $3.7 \%$ & $72.7 \%$ & & & \\
\hline & TV ads & $27.5 \%$ & $3.3 \%$ & $69.2 \%$ & & & \\
\hline & Other channels & $35.0 \%$ & $11.1 \%$ & $53.9 \%$ & & & \\
\hline \multirow{6}{*}{$\begin{array}{c}\text { Reasons to } \\
\text { come }\end{array}$} & Tourism & $24.4 \%$ & $2.9 \%$ & $72.7 \%$ & \multirow{6}{*}{0.0306} & \multirow{6}{*}{0.0002} & \multirow{6}{*}{0.0000} \\
\hline & Work & $28.0 \%$ & $5.1 \%$ & $66.9 \%$ & & & \\
\hline & Refugees & $19.4 \%$ & $1.0 \%$ & $79.7 \%$ & & & \\
\hline & Studies & $39.4 \%$ & $8.0 \%$ & $52.6 \%$ & & & \\
\hline & Retirement & $30.2 \%$ & $4.8 \%$ & $64.9 \%$ & & & \\
\hline & Other reasons to come & $31.2 \%$ & $15.8 \%$ & $53.1 \%$ & & & \\
\hline \multirow{4}{*}{$\begin{array}{l}\text { House } \\
\text { location }\end{array}$} & Historical center & $23.3 \%$ & $5.2 \%$ & $71.5 \%$ & \multirow{4}{*}{0.0015} & \multirow{4}{*}{0.4797} & \multirow{4}{*}{0.0029} \\
\hline & Urban area & $25.3 \%$ & $3.2 \%$ & $71.4 \%$ & & & \\
\hline & New urban area & $34.8 \%$ & $4.3 \%$ & $60.9 \%$ & & & \\
\hline & Rural area & $34.9 \%$ & $5.4 \%$ & $59.8 \%$ & & & \\
\hline \multirow{7}{*}{$\begin{array}{l}\text { Main } \\
\text { transport } \\
\text { mode }\end{array}$} & Walking & $26.9 \%$ & $3.4 \%$ & $69.7 \%$ & \multirow{7}{*}{0.0433} & \multirow{7}{*}{0.0004} & \multirow{7}{*}{0.0001} \\
\hline & Bike & $32.4 \%$ & $11.2 \%$ & $56.4 \%$ & & & \\
\hline & Public transport & $24.1 \%$ & $2.7 \%$ & $73.1 \%$ & & & \\
\hline & Private car & $30.1 \%$ & $2.8 \%$ & $67.1 \%$ & & & \\
\hline & Motorcycle & $32.4 \%$ & $12.4 \%$ & $55.2 \%$ & & & \\
\hline & Taxi & $19.8 \%$ & $3.3 \%$ & $76.9 \%$ & & & \\
\hline & Other transport mode & $14.7 \%$ & $0.4 \%$ & $84.9 \%$ & & & \\
\hline \multirow{6}{*}{ Income } & ECS 300 or less & $28.4 \%$ & $8.5 \%$ & $63.2 \%$ & \multirow{6}{*}{0.0002} & \multirow{6}{*}{0.0055} & \multirow{6}{*}{0.0000} \\
\hline & ECS 301-600 & $21.4 \%$ & $3.3 \%$ & $75.3 \%$ & & & \\
\hline & ECS 601-900 & $22.9 \%$ & $2.7 \%$ & $74.4 \%$ & & & \\
\hline & ECS 901-1200 & $36.0 \%$ & $2.4 \%$ & $61.6 \%$ & & & \\
\hline & ECS 1201-1500 & $31.4 \%$ & $1.6 \%$ & $67.1 \%$ & & & \\
\hline & More than ECS 1500 & $31.5 \%$ & $7.2 \%$ & $61.3 \%$ & & & \\
\hline \multirow{3}{*}{$\begin{array}{l}\text { Main income } \\
\text { source }\end{array}$} & Salary & $24.0 \%$ & $3.2 \%$ & $72.8 \%$ & \multirow{3}{*}{0.0476} & \multirow{3}{*}{0.0304} & \multirow{3}{*}{0.0031} \\
\hline & Self-employed salary & $29.2 \%$ & $3.0 \%$ & $67.7 \%$ & & & \\
\hline & Other income source & $29.3 \%$ & $6.4 \%$ & $64.3 \%$ & & & \\
\hline
\end{tabular}

${ }^{1}$ The figures represent the average probabilities. ${ }^{2}$ The figures represent the probability value of the Tukey-Kramer coefficient that can be used to determine the confidence level for which the differences in the probability values are observed for the exigent, unneeded and intermediate immigrants.

The ANOVA results show that exigent immigrants are more numerous when: (1) they receive the information from other channels; (2) they come for studies; (3) they live in the new urban area or in the rural area; (4) they use bikes or motorcycles as the main mode of transport; (5) they are more affluent; and (6) their main source of income comes from self-employment or rent. On the other hand, there are more numerous unneeded immigrants when: (1) they receive the information from other channels; (2) they have other reasons to come; (3) they use bikes or motorcycles as the main mode of transport; (4) they present a duality with respect to the income (lowest and highest income group are more represented in the cluster); and (5) the main source of income comes from rent.

\section{Discussion}

\subsection{Fuzzy Hybrid Model}

It was seen that for the average immigrant, the highest valued items were quality of urban services, programs for foreigners, house rental costs, climate, lifestyle, ease of integration, safety, cost of living, medical assistance and quality of water. Meanwhile, there were only two items for which the immigrants in Cuenca were not very exigent, namely sport facilities and education. The comparison of the results with previous studies cannot be directly extracted as several previous studies have analyzed the influence of 
the determinants for explaining the dependent variable to emigrate or not, and not the influence of each determinant on a synthetic exigency scale as in our case. Nevertheless, the comparison will provide interesting insights into the results obtained in the study.

Migration can be explained by multiple factors, and among them, the most important drivers are the advantageous exchange rate of the currencies between the destination and the origin of the pension, low costs of living and adequate medical services [66]. A warmer climate and lower cost of living are also important drivers to emigrate to other countries for pensioner migrations in Japan, Italy, Great Britain and the United States [67].

It seems that when societies become more prosperous, seniors tend to move to milder climate areas in which their cost of living is lower. This evidence is in line with the findings of $[21,32,34]$, in which the main determinants for immigrants are not exclusively formed by the mild climate and proximity to the sea, but also for the beautiful landscape, culture, gastronomy and a good presence of commercial areas. For example, the pensioner migration from Great Britain to Tuscany has a long tradition, and the destination is selected because of its mild climate conditions, the seaside proximity, its beautiful landscape, high culture, and its great lifestyle immortalized with the concept of the Italian "dolce vita" [34].

Regarding the programs for pensioners, the results are in the same line of $[27,34,68]$, in which individuals choose their emigration destinations due to policies that support pensioners and foreigners from host countries, but above all, they require to be able to take advantage of medical assistance. In this context, retirees spend a high monthly average fee on taxes, entertainment, medical services, and so on in their destinations. This means that emigrating to a less developed country allows them to live a comfortable life for less. Two types of immigrants can be distinguished: those who aim to improve the quality of their life by spending less than in their countries of origin and those who, on the other hand, emigrate to find a warm climate and fun at all costs [34].

From our analysis, it emerged that there were some factors that immigrants do not consider very much when choosing a destination to emigrate. Although, young people from the southern hemisphere dream successfully of sport that generates migratory flows to the countries of the northern hemisphere [69], this finding has not been empirically supported by our results. Similarly, to findings in [70], education could be a stimulus to emigrate but this is not necessarily supported by all the immigrants.

Regarding, the house location, our results concurred with [35], in which migrants move to rural areas to ensure a peaceful lifestyle, seeking a peaceful environment from their destinations to be able to spend a peaceful life. In fact, according to the analysis of [71], emigrants consider green space, access to good water, and air quality to be important. For example, the authors found that urban residents had better access to clean water because China's government gave a higher priority to the quality of drinking water in urban areas than in rural areas.

The analysis of the positive ideal solutions concluded that some additional items are highly valued by some population groups, such as access to internet and benefits for retirees. In addition, the percentage variation between the values of the positive and negative ideal solutions was used to conclude that four items were seen more homogeneously by the immigrants, namely quality of water and air, language and social atmosphere. Meanwhile, only one item, banks and monetary exchange, was seen very heterogeneously.

Digital nomads are defined as individuals who can work remotely from any location, taking advantage of portable computing technologies and widespread internet access [72]. For this group of immigrants characterized by lifestyles based on mobility, minimalism (unneedful orientation), uncertainty and being risk-takers instead of having a sedentary life, materialism, stability and comfort, internet access is absolutely crucial. These new immigrants could select any city of the world which could develop vibrant communities that facilitate the participation in professional and social networks, with good weather, fast internet access and a minimum cost of living.

Regarding pensioners, it was found that due to their growing financial independence and improved health, retirees are nowadays more pushed to emigrate not for work reasons, 
but rather to improve their health, standards of living as well as and environmental conditions [69].

The synthetic index was used to analyze immigration in Cuenca for a number of population groups based on nationality, gender, age, marital status and whether the immigrants are retired or not. The results showed that Peruvians, Mexicans, Venezuelans and Cubans were the most exigent immigrants of the whole set of nationalities. Females were more exigent than males. The senior age immigrants were more exigent than other age groups. The widowed and unmarried couple immigrants were more exigent than other marital status groups. And finally, retired immigrants were more exigent than non-retired immigrants.

Freirer and Holloway [14] used mixed methods to find that "a Cuban interviewee explained, how she chose Ecuador for many reasons, first because it is a country that is very open to tourists, immigrants, the world. It is a country more open to the world, and apart from that because of the Spanish language, there is a great amount of mixture of Latinos, here in Ecuador, the same Colombians, Peruvians". Thus, it can be inferred that cultural values that are shared by Hispanic heritage can play a determinant role explaining the exigency index.

Age is an important determinant for the number of immigrants at aggregated country levels because a young age structure in the destination was found to be positively associated with a lower number of immigrants, while a young age structure in the origin was associated with a higher number of immigrants [20].

Palloni et al. [22] contended that gender captured unmeasured factors that influenced the propensity to migrate. In particular, many cultural factors, such as household heads, siblings' education, and patriarchal vs. matriarchal roles are highly affected by gender. For example, in many countries the female role is mainly seen as a follower instead of a leader in issues related to reasons to emigrate.

\subsection{Elasticities, Fuzzy Clustering and ANOVA}

The analysis of elasticities showed that the average immigrant in Cuenca is more elastic with respect to: (1) banks and monetary exchange; (2) benefits for retirees; and (3) access to internet; and more inelastic with respect to: (1) language; (2) accessibility of roads; and (3) means of transport. The three profiles for the fuzzy clusters' representatives were found to be a very extreme exigent American immigrant who answered that every item of the scale was very important, a very extreme unneedful Bolivian immigrant who answered that all the items of the scale were not important at all with the exception of the climate (somewhat important), and finally a Dutch immigrant who was the representative for the intermediate exigent cluster obtained a score of 120 on the scale, which is closer to the extreme exigent representative than to the extreme unneedful representative. The results showed that the immigrants in Cuenca are more similar to the intermediate and the extreme exigent representatives than to the exigent unneedful representative. The probability of the latter cluster was only 4.1 percent, so unneedful immigrants are not common in Cuenca.

The ANOVA results showed that a number of variables had a significant effect on the probability of belonging to the three fuzzy clusters, namely information channels, reasons to come, house location, main transport mode, income, expenditure in the city and main income source. Specifically, the exigent immigrants were found to be more numerous when: (1) they received the information from other channels; (2) they came for studies; (3) they lived in the new urban area or in the rural area; (4) they used bikes or motorcycles as the main mode of transport; (5) they were more affluent; and (6) their main source of income came from self-employment or rent. On the other hand, more numerous unneeded immigrants were found when: (1) they received the information from other channels; (2) they had other reasons to come; (3) they used bikes or motorcycles as the main mode of transport; (4) they presented a duality with respect to the income (lowest and highest income group were more represented in the cluster); and (5) the main source of income came from rent. 
Other information channels usually refer to friends or relatives who have previously emigrated to Cuenca, and this result is concordant with [70,73], as migration is highly influenced by the size of the network of previous migrants at destination. It seems evident that those who plan to emigrate to Cuenca, whenever possible, will connect with past migrants to establish the main advantages and disadvantages about Cuenca, thereby significantly reducing the transaction costs of gathering information. It seems also reasonable to highlight that the number of migrants in Cuenca could also be used as an important source of social capital that enhances the lifestyle and well-being of immigrants. There are also specialized media channels that have created a ranking of the best cities to live, and internet access is popularizing this type of information. Real estate dealers have also developed websites with detailed information about many aspects of seniors' life. There are also other social media channels, such as Facebook and twitter accounts, that provide sharing experiences of other immigrants in different destinations.

Regarding the main income source and transport modes, it was not easy to find any comparable evidence. Marjavaara [35] analyzed a cohort of Swedish residents aged 55-70 years to study the retirement transition migration because they argued that this cohort could be compared to that of retirement-age persons. They contended that the migrant drivers are quite similar to those of the cohort of having an empty nest, which is preparing its lifestyle for a transition to the age of retirement. Meanwhile, the issue of the main transport mode used by immigrants in the less developed countries has been clearly unexplored. In Canada, young people appeared to be using public transit more than the previous generations, reversing twentieth century trends, but the importance of such findings depends on whether high transit and other more environmental transport modes use could be affected by residents' lifestyles [74].

\section{Conclusions}

The migratory phenomenon has been extensively studied as a phenomenon of income of new migrants into European and North American countries. On the other hand, however, there are very distinct realities, such as the case of Ecuador, an upper-middle-income country according to the World Bank, which can be considered both a relatively safe and economically attractive southern destination that can be used as a migratory intermediate stop toward North America [14] that has not been analyzed very much. Paradoxically, Rafael Correa, a former president of Ecuador, promoted a number of legislations that favor the entrance of migrants to the country through guaranteeing universal citizenship and free human mobility in a period in which there was also a massive Ecuadorian emigration. Freier and Holloway [14] recommended migration scholars to better reconceptualize immigrants' drivers beyond simplistic assumptions based on economic motivation and well-being improvements. They also contended that restrictive migrant policies of high-income countries will divert some of the immigrants to the South. Our study contributes to both of the commented issues with a more profound analysis beyond economic and well-being motivations, and with an analysis of a city located in Ecuador. Thus, the study analyses the exigencies of immigrants residing in Cuenca, Ecuador based on a fuzzy hybrid method and a fuzzy clustering method providing some insights on the little knowledge that exists in this region of the world.

As stated, the analysis is based on two related methods: a fuzzy hybrid TOPSIS method and a fuzzy clustering method that have been previously applied in other contexts $[8,39,60,64,65]$. Results provide interesting insights that were already discussed. First, the importance given to the different items included in the scale is very heterogeneous across different population groups. Second, the fuzzy clustering approach used in the study provides a more flexible characterization of immigrants than other classical clustering methods, and the partitioning around the three selected real immigrants instead of centroids used in other studies are more suitable for results interpretation. The membership coefficients obtained in the fuzzy clustering were analyzed through ANOVA, and results showed that there are some covariates, which have a significant effect on the probability of 
giving more or less importance to the scale items, such as information channels, reasons to come, house location, main transport mode, income, expenditure in the city and main income source. It was also interesting to note that the same covariate could have a significant effect for being positively associated to extreme exigent and unneedful immigrants. These results should be taken into account for those policy makers in charge of developing immigration policies in Ecuador.

This study is not exempt from a number of limitations that could be studied in a future agenda. For example, the scale to study the importance given to some attributes in order to emigrate to a different country is still under researched, and a more suitable and robust scale needs to be developed. Other interesting issues that can be analyzed in the future are more related to the fuzzy clustering method regarding to the effects of the fuzziness coefficient $m$, the values of the $w$ coefficients that can be internally calculated within the model or the selection of other medoids in order to analyze the stability of the results.

Author Contributions: Conceptualization, J.C.M. and N.S.B.-S.; methodology, J.C.M.; software, J.C.M. and A.I.; validation, J.C.M., N.S.B.-S. and A.I.; investigation, N.S.B.-S.; resources, N.S.B.-S.; data curation, N.S.B.-S.; writing-original draft preparation, J.C.M., N.S.B.-S. and A.I.; writing-review and editing, J.C.M. All authors have read and agreed to the published version of the manuscript.

Funding: This research received no external funding.

Institutional Review Board Statement: Not applicable.

Informed Consent Statement: Informed consent was obtained from all subjects involved in the study.

Data Availability Statement: The datasets generated during the current study are not publicly available due to participants' confidentiality but are available from the corresponding author on reasonable request.

Acknowledgments: We acknowledge the support given by some colleagues at the Universidad de Cuenca as well as at the Universidad Técnica Particular de Loja during the focus group when the questionnaire was designed. The help received by the master's students for the questionnaire administration is also highly appreciated. We also acknowledge the constructive comments raised by the editor and three anonymous reviewers.

Conflicts of Interest: The authors declare no conflict of interest.

\section{References}

1. De Coninck, D. Migrant categorizations and European public opinion: Diverging attitudes towards immigrants and refugees. J. Ethn. Migr. Stud. 2020, 46, 1667-1686. [CrossRef]

2. Goodman, S.; Burke, S.; Liebling, H.; Zasada, D. 'I Can't Go Back Because If I Go Back I Would Die': How Asylum Seekers Manage Talk about Returning Home by Highlighting the Importance of Safety. J. Community Appl. Soc. Psychol. 2015, 25, 327-339. [CrossRef]

3. Heath, A.; Davidov, E.; Ford, R.; Green, E.G.T.; Ramos, A.; Schmidt, P. Contested terrain: Explaining divergent patterns of public opinion towards immigration within Europe. J. Ethn. Migr. Stud. 2020, 46, 475-488. [CrossRef]

4. Hatton, T.J. Public opinion on immigration in Europe: Preference and salience. Eur. J. Polit. Econ. 2020, 66, 101969. [CrossRef]

5. Meuleman, B.; Abts, K.; Schmidt, P.; Pettigrew, T.F.; Davidov, E. Economic conditions, group relative deprivation and ethnic threat perceptions: A cross-national perspective. J. Ethn. Migr. Stud. 2020, 46, 593-611. [CrossRef]

6. Davidov, E.; Seddig, D.; Gorodzeisky, A.; Raijman, R.; Schmidt, P.; Semyonov, M. Direct and indirect predictors of opposition to immigration in Europe: Individual values, cultural values, and symbolic threat. J. Ethn. Migr. Stud. 2020, 46, 553-573. [CrossRef]

7. Martín, J.C.; Indelicato, A. A DEA MCDM Approach Applied to ESS8 Dataset for Measuring Immigration and Refugees Citizens' Openness. J. Int. Migr. Integr. 2021, 1-21. [CrossRef]

8. Martín, J.C.; Bustamante-Sánchez, N.S. A cultural analysis of the secondary housing tourism in Vilcabamba, Ecuador. Int. J. Hous. Mark. Anal. 2019, 12, 604-625. [CrossRef]

9. Jaakson, R. Second-home domestic tourism. Ann. Tour. Res. 1986, 13, 367-391. [CrossRef]

10. Gustafson, P. Retirement migration and transnational lifestyles. Ageing Soc. 2001, 21, 371-394. [CrossRef]

11. Hall, K.; Hardill, I. Retirement migration, the "other" story: Caring for frail elderly British citizens in Spain. Ageing Soc. 2016, 36, 562-585. [CrossRef] [PubMed]

12. Alba, R.; Foner, N. Strangers No More: Immigration and the Challenges of Integration in North America and Western Europe; Princeton University Press: Princeton, NJ, USA, 2015; ISBN 9781400865901. 
13. Hayes, M. "Sometimes you gotta get out of your comfort zone": Retirement migration and active ageing in Cuenca, Ecuador. Ageing Soc. 2021, 41, 1221-1239. [CrossRef]

14. Freier, L.F.; Holloway, K. The Impact of Tourist Visas on Intercontinental South-South Migration: Ecuador's Policy of "Open Doors" as a Quasi-Experiment. Int. Migr. Rev. 2019, 53, 1171-1208. [CrossRef]

15. Hanson, G.H.; Robertson, R.; Spilimbergo, A. Does Border Enforcement Protect U.S. Workers from Illegal Immigration? Rev. Econ. Stat. 2002, 84, 73-92. [CrossRef]

16. Stringer, A. Crossing the Border: Latino Attitudes toward Immigration Policy. J. Int. Migr. Integr. 2018, 19, 701-715. [CrossRef]

17. Miyagiwa, K.; Sato, Y. Illegal immigration, unemployment, and multiple destinations. J. Reg. Sci. 2019, 59, 118-144. [CrossRef]

18. De Haas, H. A theory of migration: The aspirations-capabilities framework. Comp. Migr. Stud. 2021, 9, 8. [CrossRef]

19. Pagogna, R.; Sakdapolrak, P. Disciplining migration aspirations through migration-information campaigns: A systematic review of the literature. Geogr. Compass 2021, 15, e12585. [CrossRef]

20. Kim, K.; Cohen, J.E. Determinants of International Migration Flows to and from Industrialized Countries: A Panel Data Approach beyond Gravity. Int. Migr. Rev. 2010, 44, 899-932. [CrossRef]

21. Aziz, N.; Chowdhury, M.; Cooray, A. Why do people from wealthy countries migrate? Eur. J. Polit. Econ. 2021, 102156. [CrossRef]

22. Palloni, A.; Massey, D.S.; Ceballos, M.; Espinosa, K.; Spittel, M. Social Capital and International Migration: A Test Using Information on Family Networks. Am. J. Sociol. 2001, 106, 1262-1298. [CrossRef]

23. Williams, N.E.; Hughes, C.; Bhandari, P.; Thornton, A.; Young-DeMarco, L.; Sun, C.; Swindle, J. When Does Social Capital Matter for Migration? A Study of Networks, Brokers, and Migrants in Nepal. Int. Migr. Rev. 2020, 54, 964-991. [CrossRef] [PubMed]

24. Thielemann, E.R. How Effective are National and EU Policies in the Area of Forced Migration? Refug. Surv. Q. 2012, 31, 21-37. [CrossRef]

25. Jo, H.M. Constitutionalizing trans-border nationhood: From Latin American perspectives. Asian J. Law Soc. 2020, 7, 61-84. [CrossRef]

26. Doña Reveco, C.; Finn, V. Conflicting Priorities in South American Migration Governance. Bull. Lat. Am. Res. 2021, 1-16. [CrossRef]

27. Palop-García, P.; Pedroza, L. Do Diaspora Engagement Policies Endure? An Update of the Emigrant Policies Index (EMIX) to 2017. Glob. Policy 2021, 12, 361-371. [CrossRef]

28. Hammoud-Gallego, O. A Liberal Region in a World of Closed Borders? The Liberalization of Asylum Policies in Latin America, 1990-2020. Int. Mig. Rev. 2022, 56, 63-96. [CrossRef]

29. Solano, G.; Wali, A.; Yar, A. Gaps in Migration Research. Review of Migration Theories and the Quality and Compatibility of Migration Data on the National and International Level. Migration Policies at the Local Level: The Case of Belgian Municipalities View Project; HIVA-Research Institute for Work and Society: Leuven, Belgium, 2020.

30. Pedroza, L.; Palop-García, P. Diaspora policies in comparison: An application of the Emigrant Policies Index (EMIX) for the Latin American and Caribbean region. Polit. Geogr. 2017, 60, 165-178. [CrossRef]

31. Müller, D.K. 20 years of Nordic second-home tourism research: A review and future research agenda. Scand. J. Hosp. Tour. 2021, 21, 91-101. [CrossRef]

32. Stylidis, D.; Cherifi, B.; Melewar, T.C. Exploring Czechs' and Greeks' mental associations of London: A tourist destination or a place to live in? J. Destin. Mark. Manag. 2021, 19, 100530. [CrossRef]

33. Müller, D.K.; Hoogendoorn, G. Second Homes: Curse or Blessing? A Review 36 Years Later. Scand. J. Hosp. Tour. 2013, 13, 353-369. [CrossRef]

34. Pytel, S.; Rahmonov, O.; Ruman, M. Internal and external migrations of pensioners in Poland: A directional typology. Popul. Space Place 2020, 26, e2330. [CrossRef]

35. Marjavaara, R.; Lundholm, E. Does Second-Home Ownership Trigger Migration in Later Life? Popul. Space Place 2016, 22, 228-240. [CrossRef]

36. Behdioğlu, S.; Acar, E.; Burhan, H.A. Evaluating service quality by fuzzy SERVQUAL: A case study in a physiotherapy and rehabilitation hospital. Total Qual. Manag. Bus. Excell. 2019, 30, 301-319. [CrossRef]

37. Martínez, M.P.; Cremasco, C.P.; Gabriel Filho, L.R.A.; Braga Junior, S.S.; Bednaski, A.V.; Quevedo-Silva, F.; Correa, C.M.; da Silva, D.; Moura-Leite Padgett, R.C. Fuzzy inference system to study the behavior of the green consumer facing the perception of greenwashing. J. Clean. Prod. 2020, 242, 116064. [CrossRef]

38. Leon, S.; Martín, J.C. A fuzzy segmentation analysis of airline passengers in the U.S. based on service satisfaction. Res. Transp. Bus. Manag. 2020, 37, 100550. [CrossRef]

39. Martin, J.C.; Román, C.; Moreira, P.; Moreno, R.; Oyarce, F. Does the access transport mode affect visitors' satisfaction in a World Heritage City? The case of Valparaiso, Chile. J. Transp. Geogr. 2021, 91, 102969. [CrossRef]

40. Herrera, F.; Herrera-Viedma, E. Linguistic decision analysis: Steps for solving decision problems under linguistic information. Fuzzy Sets Syst. 2000, 115, 67-82. [CrossRef]

41. Zadeh, L.A. Fuzzy Sets. Inf. Control 1965, 8, 338-353. [CrossRef]

42. Zimmermann, H.J. Fuzzy Set Theory and Its Applications, 2nd ed.; Springer Science: Berlin/Heidelberg, Germany, 2013.

43. Mendel, J.M. Uncertain Rule-Based Fuzzy Logic Systems: Introduction and New Directions, 2nd ed.; Springer: Cham, Switzerland, 2017.

44. Kaufmann, A.; Gupta, M.M. Introduction to Fuzzy Arithmetic Theory and Application; Van Nortrand Reinhold: New York, NY, USA, 1985. 
45. Zimmermann, H.J. Fuzzy Set Theory and Its Applications, 4th ed.; Kluwer Academic Publishers: Nowell, MA, USA, 2001; ISBN 9789401038706

46. Bector, C.R.; Chandra, S. Fuzzy Mathematical Programming and Fuzzy Matrix Games; Springer: Berlin/Heidelberg, Germany, 2005; ISBN 3-540-23729-1.

47. Mamdani, E.H.; Assilian, S. An Experiment in Linguistic Synthesis with a Fuzzy Logic Controller. Int. J. Man-Mach. Stud. 1975, 7, 1-13. [CrossRef]

48. Zadeh, L.A. The Concept of a Linguistic Variable and its Application to Approximate Reasoning-I. Inf. Sci. 1975, 8, 199-249. [CrossRef]

49. Hwang, C.; Yoon, K. Multiple Attribute Decision Making: Methods and Application; Springer: New York, NY, USA, 1981.

50. Chen, C. Extensions of the TOPSIS for group decision-making under fuzzy environment. Fuzzy Sets Syst. 2000, 114, 1-9. [CrossRef]

51. Chu, T.C. Selecting plant location via a fuzzy TOPSIS approach. Int. J. Adv. Manuf. Technol. 2002, 20, 859-864. [CrossRef]

52. Chen, C.T. A fuzzy approach to select the location of the distribution center. Fuzzy Sets Syst. 2001, 118, 65-73. [CrossRef]

53. Buckley, J.J. Ranking alternatives using fuzzy numbers. Fuzzy Sets Syst. 1985, 15, 21-31. [CrossRef]

54. Li, D.F. Compromise ratio method for fuzzy multi-attribute group decision making. Appl. Soft Comput. J. 2007, 7, 807-817. [CrossRef]

55. Zhao, R.; Govind, R. Algebraic characteristics of extended fuzzy numbers. Inf. Sci. 1991, 54, 103-130. [CrossRef]

56. Kaufman, A.; Gupta, M. Fuzzy Mathematical Models in Engineering and Management Science; Elsevier: New York, NY, USA, 1988.

57. Chen, S.-M. Evaluating weapon systems using fuzzy arithmetic operations. Fuzzy Sets Syst. 1996, 77, 265-276. [CrossRef]

58. Zeleny, M. Multiple Criteria Decision Making; McGraw-Hill: New York, NY, USA, 1982.

59. D'Urso, P.D. Clustering of fuzzy data. In Advances in Fuzzy Clustering and Its Applications; Valente de Oliveira, J., Pedrycz, W., Eds.; J. Wiley and Sons: Chichester, UK, 2007; pp. 155-192.

60. D’Urso, P.D.; Disegna, M.; Massari, R.; Osti, L. Fuzzy segmentation of postmodern tourists. Tour. Manag. 2016, 55, 297-308. [CrossRef]

61. Caruso, G.; Gattone, S.A.; Balzanella, A.; Di Battista, T. Cluster Analysis: An Application to a Real Mixed-Type Data Set. In Models and Theories in Social Systems; Flaut, C., Hošková-Mayerová, Š., Flaut, D., Eds.; Springer International Publishing: Cham, Switzerland, 2019; pp. 525-533. ISBN 978-3-030-00084-4.

62. Dolnicar, S.; Leisch, F. Segmenting Markets by Bagged Clustering. Australas. Mark. J. 2004, 12, 51-65. [CrossRef]

63. D'Urso, P.; Giordani, P. A weighted fuzzy c -means clustering model for fuzzy data. Comput. Stat. Data Anal. 2006, 50, 1496-1523. [CrossRef]

64. D’Urso, P.; Disegna, M.; Massari, R.; Prayag, G. Knowledge-Based Systems Bagged fuzzy clustering for fuzzy data: An application to a tourism market. Knowl.-Based Syst. 2015, 73, 335-346. [CrossRef]

65. Martín, J.C.; Moreira, P.; Román, C. A hybrid-fuzzy segmentation analysis of residents' perception towards tourism in Gran Canaria. Tour. Econ. 2020, 26, 1282-1304. [CrossRef]

66. Aguila, E.; Zissimopoulos, J. Retirement and health benefits for Mexican migrant workers returning from the United States. Int. Soc. Secur. Rev. 2013, 66, 101-125. [CrossRef]

67. Longino, C.F.; Bradley, D.E. Geographical distribution and migration. In Aging and the Social Sciences; Binstock, R.H., Georg, L.K., Eds.; Oxford Univeristy Press: Oxford, UK, 2001; pp. 103-213.

68. Kureková, L. Welfare Systems as Emigration Factor: Evidence from the New Accession States. JCMS J. Common Mark. Stud. 2013, 51, 721-739. [CrossRef]

69. Cowper, D.C.; Longino, C.F.; Kubal, J.D.; Manheim, L.M.; Dienstfrey, S.J.; Palmer, J.M. The Retirement Migration of U.S. Veterans, 1960, 1970, 1980, and 1990. J. Appl. Gerontol. 2000, 19, 123-137. [CrossRef]

70. Van Dalen, H.P.; Groenewold, G.; Schoorl, J.J. Out of Africa: What drives the pressure to emigrate? J. Popul. Econ. 2005, 18, 741-778. [CrossRef]

71. Chen, H.; Liu, Y.; Zhu, Z.; Li, Z. Does where you live matter to your health? Investigating factors that influence the self-rated health of urban and rural Chinese residents: Evidence drawn from Chinese General Social Survey data. Health Qual. Life Outcomes 2017, 15, 78. [CrossRef]

72. Mancinelli, F. Digital nomads: Freedom, responsibility and the neoliberal order. Inf. Technol. Tour. 2020, 22, 417-437. [CrossRef]

73. Docquier, F.; Peri, G.; Ruyssen, I. The Cross-country Determinants of Potential and Actual Migration. Int. Migr. Rev. 2014, 48, 37-99. [CrossRef]

74. Grimsrud, M.; El-Geneidy, A. Transit to eternal youth: Lifecycle and generational trends in Greater Montreal public transport mode share. Transportation 2014, 41, 1-19. [CrossRef] 